\title{
Experimental Investigation of Sandstone under Cyclic Loading: Damage Assessment Using Ultrasonic Wave Velocities and Changes in Elastic Modulus
}

\author{
Sen Yang $\left(\mathbb{D},{ }^{1,2}\right.$ Nong Zhang $\mathbb{D},{ }^{1}$ Xiaowei Feng $\mathbb{D}^{1},{ }^{1}$ Jiaguang Kan, \\ Dongjiang Pan, ${ }^{1}$ and Deyu Qian ${ }^{1}{ }^{1}$ \\ ${ }^{1}$ Key Laboratory of Deep Coal Resource Mining, Ministry of Education of China, School of Mines, China University of Mining and \\ Technology, Xuzhou, Jiangsu 221116, China \\ ${ }^{2}$ Department of Energy and Mineral Engineering, G3 Center and Energy Institute, The Pennsylvania State University, \\ University Park, PA 16802, USA
}

Correspondence should be addressed to Nong Zhang; profzhangnong@163.com

Received 2 November 2017; Revised 23 February 2018; Accepted 11 March 2018; Published 11 April 2018

Academic Editor: Emanuele Reccia

Copyright (C) 2018 Sen Yang et al. This is an open access article distributed under the Creative Commons Attribution License, which permits unrestricted use, distribution, and reproduction in any medium, provided the original work is properly cited.

\begin{abstract}
This laboratory study investigated the damage evolution of sandstone specimens under two types of cyclic loading by monitoring and analyzing changes in the elastic moduli and the ultrasonic velocities during loading. During low-level cyclic loading, the stiffness degradation method was unable to describe the damage accumulations but the ultrasonic velocity measurements clearly reflected the damage development. A crack density parameter is introduced in order to interpret the changes in the tangential modulus and the ultrasonic velocities. The results show the following. (1) Low-level cyclic loading enhanced the anisotropy of the cracks. This results from the compression of intergranular clay minerals and fatigue failure. (2) Irreversible damage accumulations during cyclic loading with an increasing upper stress limit are the consequence of brittle failure in the sandstone's microstructure.
\end{abstract}

\section{Introduction}

The accumulated damage from dynamic (cyclic) loading is highly detrimental in many engineered structures like mine openings [1-4], petroleum and natural gas boreholes [5], tunnels $[6,7]$, foundations [8], and underground chambers $[9,10]$. The sources of cyclic or repetitive loading can be roughly divided into two types: (1) periodic operations including drilling, blasting, and mining; (2) sporadic vibrations including earthquakes and traffic loads. Repetitive loading-unloading opens and closes the micropores and microcracks within the rock and induces the growth of cracks. Consequently, the accumulated damage can become a potential trigger for the rapid and violent failures of largescale engineered structures.

Because this kind of damage is the cumulative destruction of bonds in the rock's microstructure, it cannot be directly measured by macroscopic scale tests [11]. The most common techniques and analytical methods used to investigate rock damage are acoustic emissions (AE), the damage energy dissipation method, and the stiffness variation method [1218]. Acoustic emissions can be used as a highly sensitive detector for the microseismic events and energy release that accompany the initiation and growth of cracks in geomaterials. However, the $\mathrm{AE}$ technique has an inherent limitation in that it cannot quantify the damage to the material because the seismic events and energy do not directly reflect the ratio of structurally damaged portion to integrity portion. For this reason, AE studies mainly focus on qualitative analyses such as where the damage is taking place.

Xie et al. [19] originally attempted to use the rock energy dissipation theory under cyclic loading conditions to quantify damage. They proposed the damage variable $D$ defined as

$$
D=1-\exp \left[-B \frac{\left|Y-Y_{0}\right|^{1 / n}}{Y^{*}}\right],
$$


where $Y$ is the dissipated damage strain energy during the loading-unloading cycle; $Y^{*}$ represents an energy dissipation per unit volume. The two parameters $B$ and $n$ are related to the mechanical properties of the rock. According to the data presented by Xie et al. [19] and Liu et al. [16], the damage variables estimated by (1) agreed with their experimental results. Nevertheless, it should be pointed out that the values of the two key parameters, $B$ and $n$, are highly dependent on the numbers returned by the stiffness variation calculation.

The stiffness variation method is quite useful for describing dynamic damage in rocks. It is based on the strain equivalence hypothesis proposed by Lemaitre [20]; the damage variable $D$ is expressed as

$$
D=1-\frac{E^{\prime}}{E},
$$

where $E$ is the elastic modulus of the undamaged material; $E^{\prime}$ is the elastic modulus of damaged material. This method quantifies the changes in degree of damage by measuring variations in the properties that are the consequence of temporal changes in the rock's microstructure. Therefore, to reveal the underlying mechanisms of damage initiation and development, an appropriate monitoring technique is required. One technique, ultrasonic velocity testing, is an attractive technique because it can provide spatial and temporal information on the inner structure of the rock. The stiffness variation method is superior compared to $\mathrm{AE}$ and damage energy dissipation for two notable reasons: (1) the damage variable $(D)$ can be directly quantified by the two elastic moduli and (2) the moduli are directly measurable.

This study investigates the evolution of damage in sandstone under two types of cyclic loading by monitoring both the variations in the elastic modulus and ultrasonic responses. We adopted the stiffness variation method for damage assessment and compared it with the results from dynamic ultrasonic velocity measurements. Finally, the influences from two different types of cyclic loading on the microstructure of the rock and the subsequent damage are discussed.

\section{Previous Studies}

2.1. Mechanical Behavior of Rock Subjected to Cyclic Loading. Rock is a type of natural material characterized by heterogeneity. The intrinsic physical and mechanical properties can be determined indirectly by performing cyclic loading tests. The stress-strain behavior of rock under cyclic loading can provide useful information for theoretical analysis and for numerical calculations for rock engineering purposes such as estimating long-term stability, creep behavior, and response to fatigue $[21,22]$.

As an effective way to quantify rock deformation, uniaxial and triaxial cyclic loading tests on laboratory-scale rock samples have been used extensively by numerous researchers. Costin and Holcomb [23] suggested that stress corrosion is a time-dependent mechanism that is most sensitive to the mean stress level, whereas cyclic fatigue is most sensitive to the amplitude of the stress cycles. Tao and Mo [24] proposed that the total deformation from cyclic loading consists of initial deformation (induced by static loading), creep deformation, and damage deformation (produced by the cyclic loading itself). Martin and Chandler [25] used a repetitive loading-unloading test to investigate the progressive failure of Lac du Bonnet granite and their results describe the influence of crack damage on crack damage stress and crackinitiation stress. Ray et al. [26] found that failure strength increased with an increase in strain rate and, furthermore, they observed an abrupt increase in strength at a strain rate of 2.5/s. Jafari et al. [27] evaluated the effects of cyclic shearing on the strength of rock joints and found that the increase in shear strength results from an increase in confining pressure. By combining the plasticity theory and the self-organization theory of cellular automata, Feng et al. [28] developed an elastoplastic cellular automaton model to numerically investigate the influence of cyclic loading on the complete stress-strain curve and on $\mathrm{AE}$ emission from a rock specimen under uniaxial compression. The results indicated that their numerical simulation reproduced some of the well-known phenomena observed by other researchers. Liu and He [9] performed a series of laboratory tests to assess the effects of confining pressure on the mechanical properties and fatigue damage evolution of sandstone samples subjected to cyclic loading. They found that, with an increase in the number of cycles, the samples gradually became plastic and irreversible deformation occurred along both the axial and lateral directions. Khaledi et al. [29] proposed an elastoviscoplasticcreep model to predict the stress-strain relationships around a rock salt cavern during cyclic loading. The constitutive model Khaledi et al. developed in that paper combined three existing models, with some modifications, to combine the positive features of the three models for the specific purpose of their investigation. This allowed their new model to be applied in different simulations with different types of loading conditions as well as different time scales.

A pronounced feature of rocks subjected to cyclic loading is fatigue. It is known that fatigue in rocks is influenced by a number of factors, for example, the confining stress, the loading rate, the loading amplitude (the maximum stress), the type and frequency of the loading cycle, and the number of cycles [10, 30]. Bagde and Petroš [31] demonstrated that the quartz content, texture, and microstructure of a rock had a huge influence on its fatigue strength. Xiao et al. [32] conducted a laboratory-scale investigation on the fatigue behaviors of granite under cyclic loading. They found that determining initial fatigue damage was vital in order to establish a unified critical damage parameter. Furthermore, their result also indicated that, in most cases, the loading induced damage was continuously amplified. By comparing the results from conventional fatigue tests with those from interval fatigue tests, Fan et al. [33] demonstrated that combined cyclic stresses can significantly influence the fatigue response of rock salt.

2.2. Ultrasonic Wave Velocities in Rock. Extensive laboratory measurements of ultrasonic wave velocities in rock samples have demonstrated that elastic wave velocities can provide valuable information about the rock's internal structure. Ultrasonic velocity in a rock sample is largely dependent 
on the water content, density, composition, and boundary conditions [34]. Gupta [35] measured the P- and S-wave velocities along three mutually perpendicular directions in a limestone cube under uniaxial compression and found that prior to failure, both P- and S-wave velocities decrease in all three directions but by different amounts. The P- to S-wave velocity ratio remained nearly constant along the loading direction, decreased slightly along the direction parallel to the shear plane, and dropped considerably along the direction perpendicular to the shear plane. By performing uniaxial cyclic loading tests on granite specimens, Rao and Ramana [12] monitored the variations in the compressional wave velocity in the direction perpendicular to the applied stress. They observed a steady rise in the compressional wave velocity with an increase in the load of up to $30 \%$ of the compressive strength. However, when the rock was loaded again to $80 \%$ of its compressive strength, the compressional wave velocity fell rapidly, indicating the development of microcracks. Stanchits et al. [36] found that P-wave velocity in basalt was about $3 \mathrm{~km} / \mathrm{s}$ at atmospheric pressure but increases by more than $50 \%$ when the hydrostatic pressure was increased to $120 \mathrm{MPa}$. In his granite samples, initial Pwave velocity was $5 \mathrm{~km} / \mathrm{s}$ but increased by less than $20 \%$ under increased pressure. Stanchits et al. proposed that the pressure-induced changes of elastic wave speed indicated dominantly compliant low-aspect ratio pores in both the basalt and the granite. Xiao et al. [32] proposed a mathematical model to quantify damage evolution in granite under cyclic loading and observed an obvious three-stage behavior reflecting the evolution of fatigue damage.

Given its high sensitivity to the inner defects in rock materials, the ultrasonic velocity technique can be used to accurately and quantitatively monitor the changes in rock fractures. This makes it possible to observe the mechanical changes in the rock. Cyclic loading tests typically produce continuous initiation and closing of cracks and these cracks cannot be adequately monitored by conventional methods and, so far, very few results from the application of the ultrasonic velocity technique to cyclic loading tests have been reported. Therefore, this work employed the ultrasonic velocity technique to investigate changes in the inner structure of rock specimens during cyclic loading.

\section{Experimental Work}

The sandstone blocks from which cores were drilled for this study were collected from an open-pit mine located in Kittanning, Pennsylvania. Dry cylindrical cores were drilled from the same large sandstone block and prepared as $50 \mathrm{~mm}$ diameter by $100 \mathrm{~mm}$ long specimens. Both ends of the specimens were ground and polished according to the ISRM standards [37] before the tests were run; prepared specimens are shown in Figure 1. In order to eliminate the influence of water, the specimens were oven-dried until their weight remained constant. Uniaxial compressive strength (UCS) and cyclic loading tests were conducted using a hydraulic servo-testing machine with a single loading rate of $50 \mathrm{~N} / \mathrm{s}$ for all the experiments. The machine had a load frame of stiffness $6000 \mathrm{kN} / \mathrm{mm}$ and a compression load

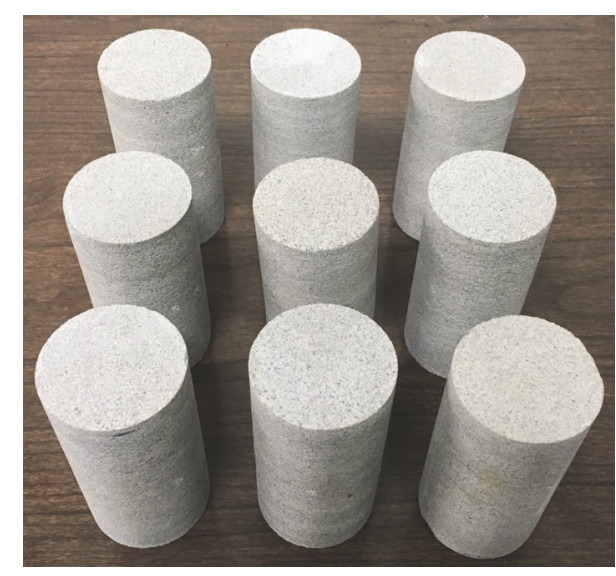

FIGURE 1: Sandstone specimen prepared for testing.

capacity of $1000 \mathrm{kN}$ with a resolution of $0.5 \%$. Its stroke was $\pm 50 \mathrm{~mm}$ with a resolution of $1 \mu \mathrm{m}$. Commercially available piezoelectric transducers with a $200 \mathrm{kHz}$ main frequency were used for both transmitting and receiving the ultrasonic signals. As illustrated in Figure 2, one piezoelectric transducer was placed between the top face of specimen and the upper, fixed platen of the hydraulic testing machine; the receiver was inserted between the bottom face of the specimen and the lower (loading) platen. The acquisition rate was set to $20 \mathrm{MHz}$ and honey was used as a couplant. Before each test, the transducers were placed against each other to determine the face-to-face arrival time so that the ultrasonic velocity could be properly determined by subtracting the face-to-face arrival time from the arrival times measured during the test. During the cyclic loading tests, the ultrasonic signals were transmitted and recorded at $4 \mathrm{MPa}$ intervals.

In order to obtain the mechanical properties of the sandstone specimens, three preliminary UCS tests were conducted. Based on those UCS data, the elastic limit and compressive strength for these specimens were determined. Then two types of cyclic loading tests were carried out, Type 1 and Type 2. In Type 1 tests, the loading was cycled between zero and a prescribed stress. This type of test was designed to investigate the effect of low-level cyclic stress on specimen damage. Because the elastic limit is widely recognized as a threshold beyond which the mechanical damage increases rapidly $[16,38-40]$, the prescribed stress was $16 \mathrm{MPa}$ lower than the elastic limit. With this $16 \mathrm{MPa}$ margin, the possibility of rapid damage resulting from specimen-to-specimen variations in the elastic limit could be avoided. The loading rate was $50 \mathrm{~N} / \mathrm{s}$; the slow rate made each experiment fairly time-consuming, so only four cycles were conducted. For Type 2 tests, the prescribed stress was progressively increased from one cycle to the next until the specimen ruptured. This test focused on damage in a high-rate damage environment; therefore the initial prescribed stress for cyclic loading was set $4 \mathrm{MPa}$ higher than the elastic limit and increased by $4 \mathrm{MPa}$ per cycle. Three replicate tests were conducted for each test type. 
TABLE 1: Mechanical properties of sandstone specimens N1, N2, and N3.

\begin{tabular}{lcccccc}
\hline Number & Peak strength/MPa & Average/MPa & Young's modulus/GPa & Average/GPa & Elastic limit/MPa & Average/MPa \\
\hline N1 & 63.22 & & 8.03 & & 54.82 & 42.79 \\
N2 & 53.07 & 55.51 & 6.96 & 7.41 & 47.14 \\
N3 & 50.24 & & 7.24 & & 43.82 & \\
\hline
\end{tabular}

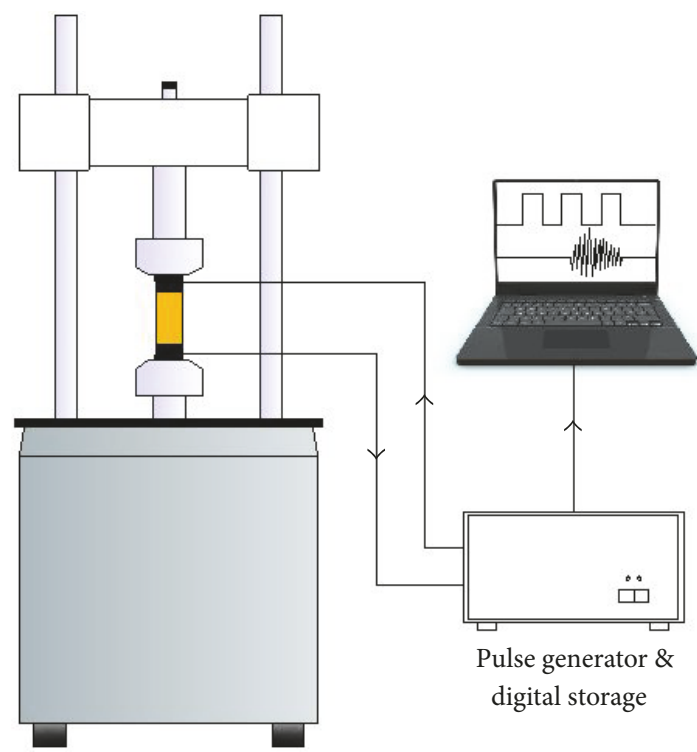

(a)

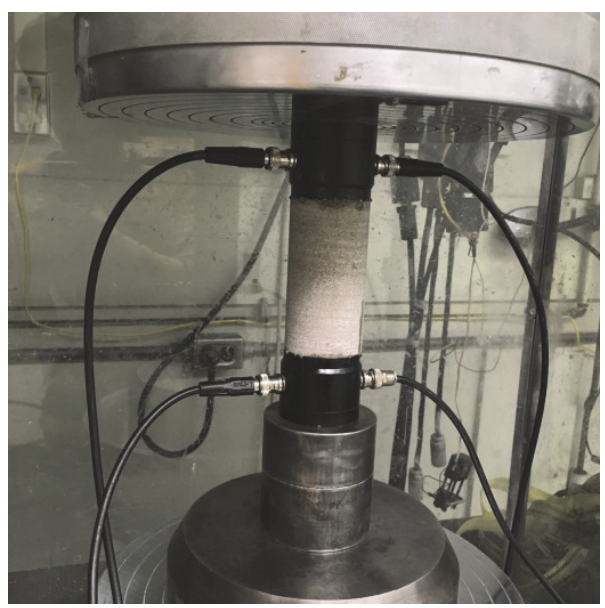

(b)

FIGURE 2: Illustrations showing the ultrasonic measurement testing system. (a) Schematic diagram. (b) Photograph of the hydraulic testing machine.

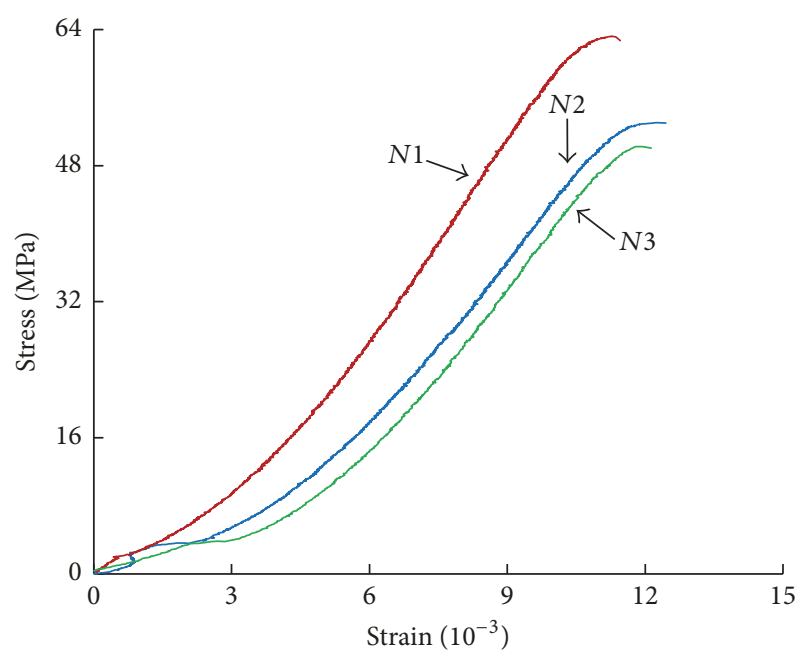

FIGURE 3: Stress-strain curves for sandstone specimens $N 1, N 2$, and $\mathrm{N} 3$ tested under uniaxial loading.

\section{Experimental Results and Discussion}

The stress-strain curves for three sandstone specimens tested under uniaxial loading are shown in Figure 3. As expected, the stress-strain curves can be divided into four stages: consolidation/compaction, elastic deformation, plastic deformation, and failure/postfailure. The overall mechanical behavior of the sandstone specimen follows that of classic brittle materials. The mechanical properties for the three specimens are listed in Table 1; the average peak strength, elastic modulus, and elastic limit are $55.51 \mathrm{MPa}, 7.41 \mathrm{GPa}$, and $47.14 \mathrm{MPa}$, respectively.

4.1. Cyclic Stress-Strain Curves and Stiffness. Based on the specimen's mechanical properties, we conducted the Type 1 and Type 2 cyclic loading experiments. Typical stress-strain curves for the two types of cyclic loading tests are shown in Figure 4. The figure shows that the hysteresis loops of tests become narrower as the number of cycles increases. The essence of the loading-unloading cycle is energy conversion in the rock specimen tested. Specifically, the area under the loading curve represents the external work absorbed by the rock and the area under the unloading curve represents the elastic strain energy released [19]. Therefore, the area of the hysteresis loop is the dissipated energy due to damage development and plastic deformation. In Figure 5, the first cycle of Figure 4(a) is shown alone to illustrate how dissipated energy and released strain energy are calculated. In Figure 5, the grey portion represents the released strain energy during 


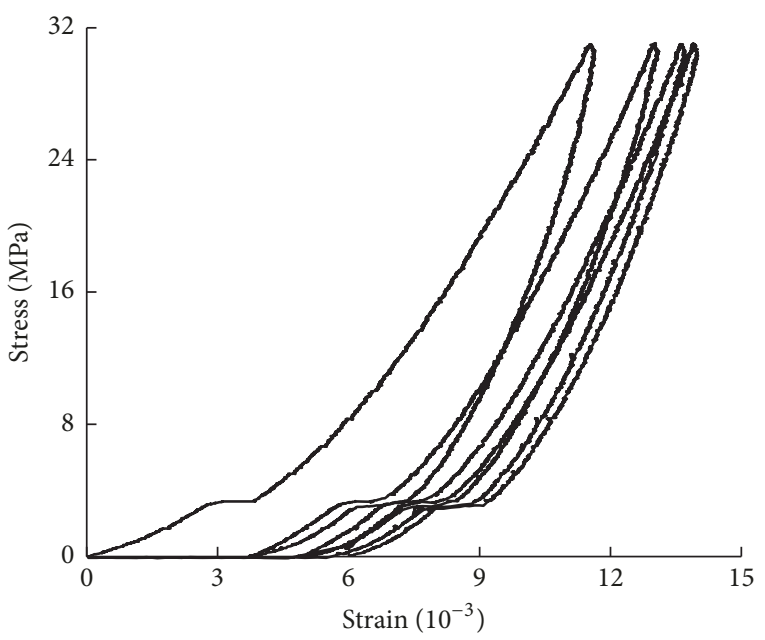

(a)

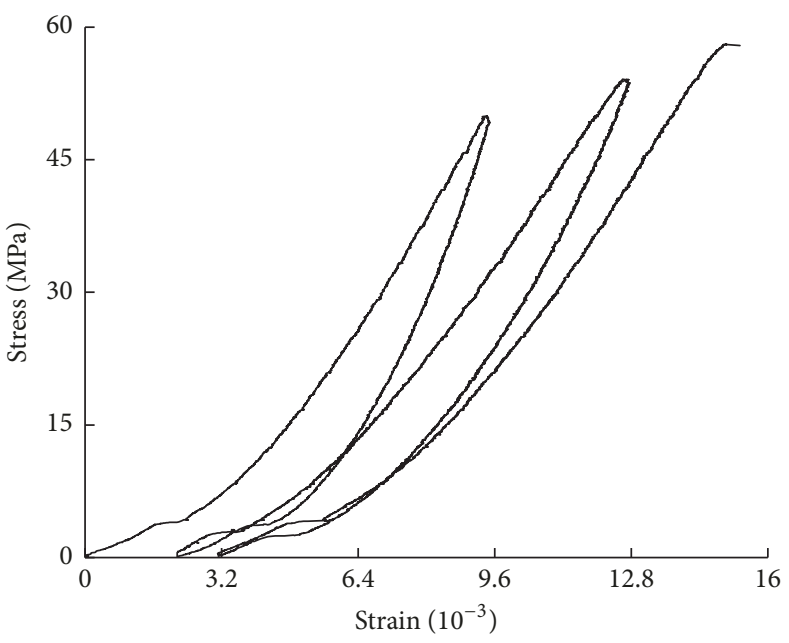

(b)

FIgURE 4: Typical stress-strain curves for cyclic loading tests. (a) Type 1; (b) Type 2.

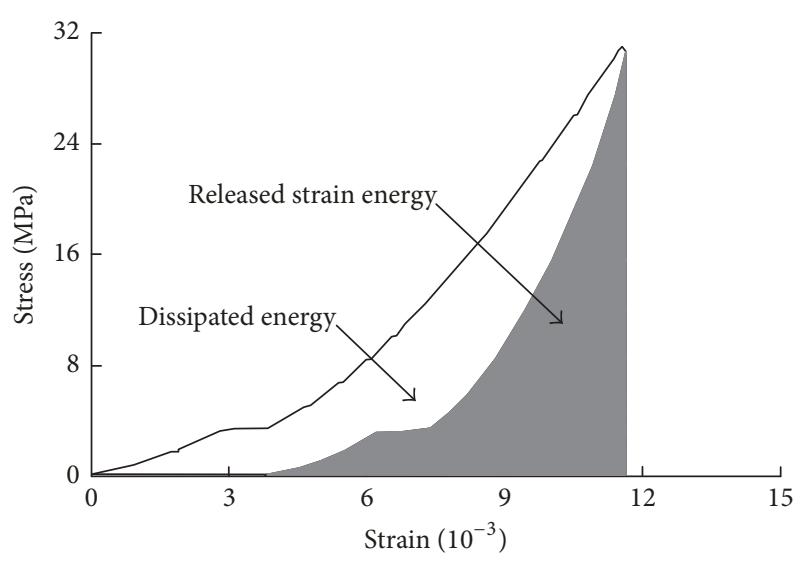

FIGURE 5: Stress-strain curve for the first cycle of Figure 4(a) illustrating the areas under the curve that represent dissipated energy and released strain energy.

the unloading phase and the white portion represents the dissipated energy. Tables 2 and 3 list the dissipated energy for the tested specimens under Type 1 and Type 2 conditions. It is clear that dissipated energy decreases as the cyclic number increases for the Type 1 test but it remains relatively constant for Type 2 test. The decrease in energy for Type 1 test can be attributed to the plastic closure of preexisting pores and cracks under cyclic loading below the specimen's elastic limit, which results in a continuous reduction of open pores and cracks. The closure of pores and cracks is also reflected by an increase in the specimens' stiffness, as shown in Table 4 where the average increase in Young's modulus for the three samples is $37.5 \%$. As for Type 2 tests, the relatively stable dissipated energy is the result of the irreversible damage produced after the elastic limit is exceeded. In Table 5, the $11.4 \%$ average decrease in Young's modulus also reflects the irreversible damage.
TABle 2: Dissipated energy for sandstone specimens under Type 1 cyclic loading tests in $\mathrm{J} / \mathrm{m}^{3}$.

\begin{tabular}{lccc}
\hline \multirow{2}{*}{ Number of cycles } & \multicolumn{3}{c}{ Number of specimens } \\
& $\# 1$ & $\# 2$ & $\# 3$ \\
\hline 1 & $6.12 \times 10^{4}$ & $6.26 \times 10^{4}$ & $5.70 \times 10^{4}$ \\
2 & $3.02 \times 10^{4}$ & $2.86 \times 10^{4}$ & $3.35 \times 10^{4}$ \\
3 & $2.21 \times 10^{4}$ & $2.77 \times 10^{4}$ & $2.62 \times 10^{4}$ \\
4 & $1.98 \times 10^{4}$ & $2.21 \times 10^{4}$ & $2.02 \times 10^{4}$ \\
\hline
\end{tabular}

TABLE 3: Dissipated energy for sandstone specimens under Type 2 cyclic loading tests in $\mathrm{J} / \mathrm{m}^{3}$.

\begin{tabular}{lccc}
\hline \multirow{2}{*}{ Number of cycles } & \multicolumn{3}{c}{ Number of specimens } \\
& $\# 1$ & $\# 2$ & $\# 3$ \\
\hline 1 & $6.49 \times 10^{4}$ & $8.69 \times 10^{4}$ & $9.30 \times 10^{4}$ \\
2 & $6.33 \times 10^{4}$ & $7.55 \times 10^{4}$ & $7.93 \times 10^{4}$ \\
\hline
\end{tabular}

TABLE 4: Young's modulus for sandstone specimens under Type 1 cyclic loading tests in GPa.

\begin{tabular}{lccc}
\hline \multirow{2}{*}{ Number of cycles } & \multicolumn{3}{c}{ Number of specimens } \\
& $\# 1$ & $\# 2$ & $\# 3$ \\
\hline 1 & 5.01 & 5.03 & 5.30 \\
2 & 5.87 & 5.36 & 5.89 \\
3 & 6.49 & 6.16 & 6.48 \\
4 & 7.25 & 6.73 & 7.10 \\
\hline
\end{tabular}

The tangential moduli calculated from Figure 4 are plotted versus axial stress in Figure 6. It is clear that the tangential moduli generally increase with increasing stress but as the cycle number increases, the moduli for Type 1 and Type 2 tests show opposite trends. For Type 1 tests, as the cycle number increases, the tangential modulus for each loading 


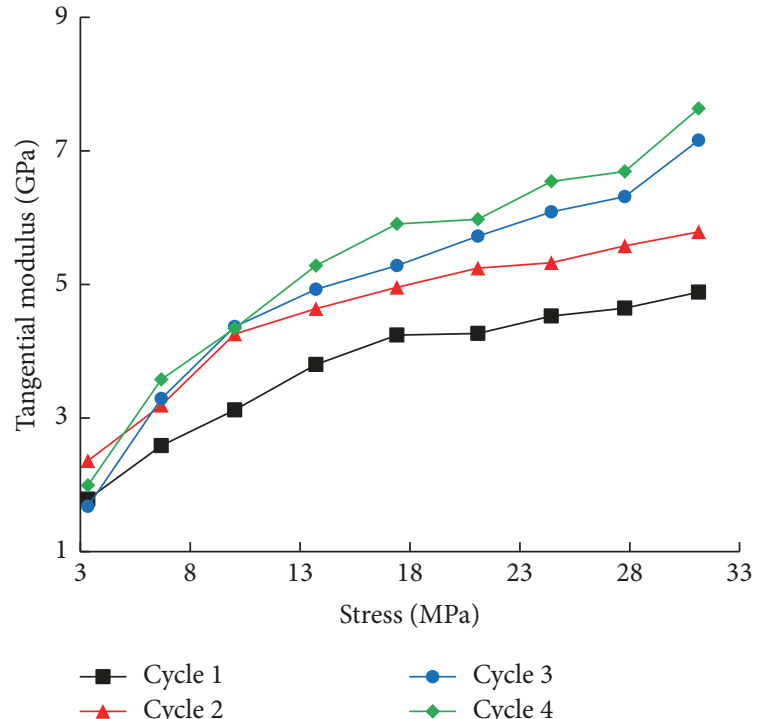

(a)

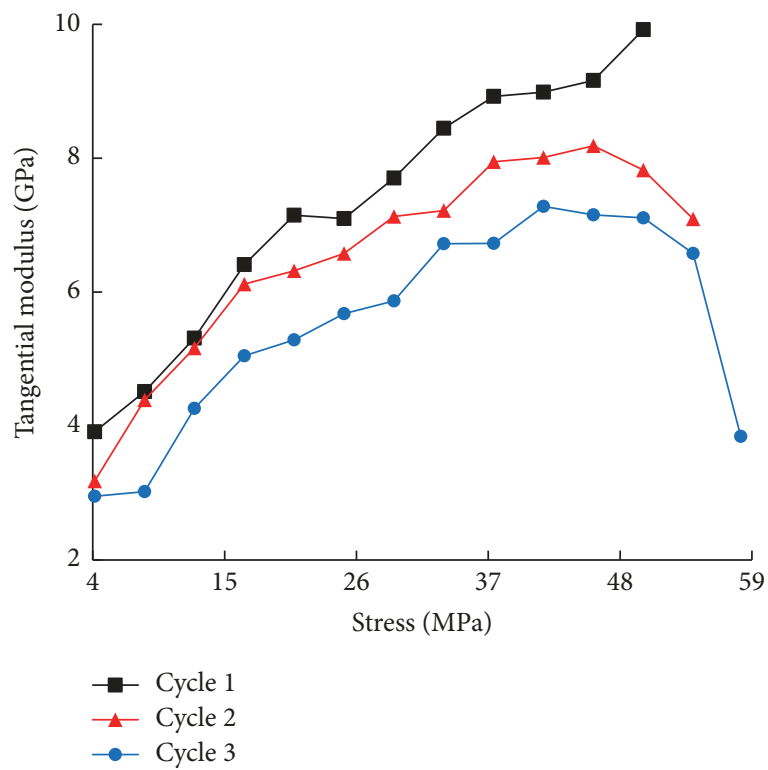

(c)

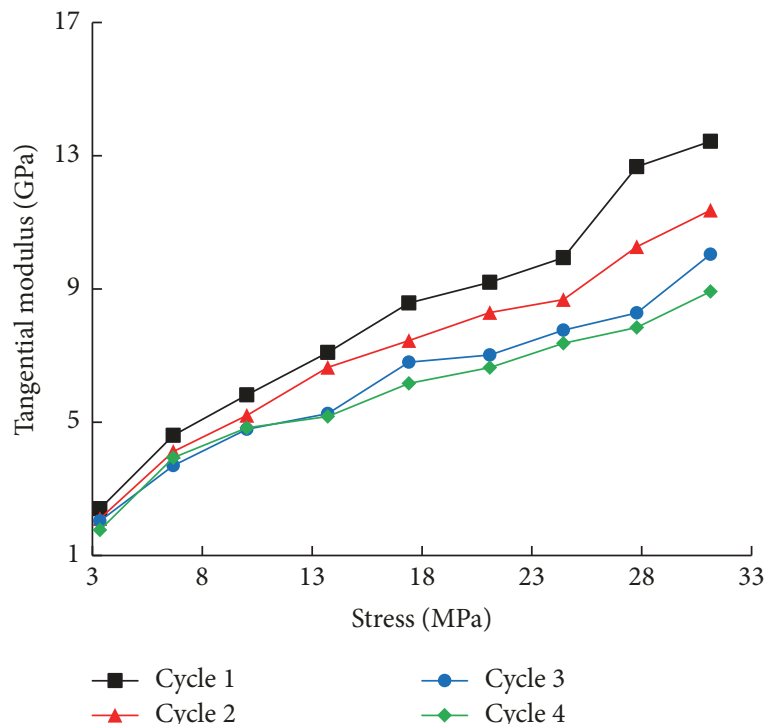

(b)

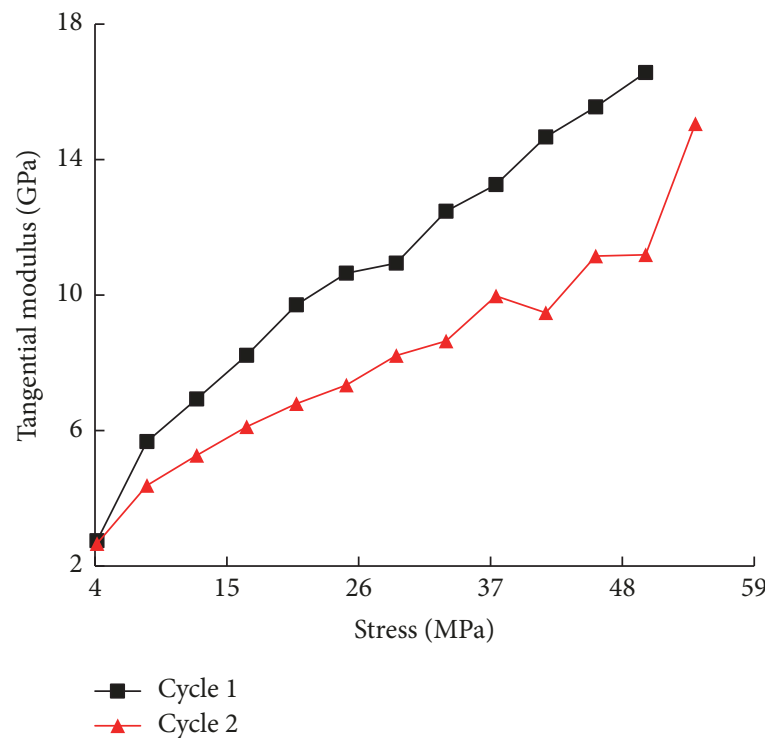

(d)

Figure 6: Graphs of tangential moduli versus axial stress for (a) Type 1 loading stages; (b) Type 1 unloading stages; (c) Type 2 loading stages; (d) Type 2 unloading stages.

TABle 5: Young's modulus for sandstone specimens under Type 2 cyclic loading tests in GPa.

\begin{tabular}{lccc}
\hline \multirow{2}{*}{ Number of cycles } & \multicolumn{3}{c}{ Number of specimens } \\
& $\# 1$ & $\# 2$ & $\# 3$ \\
\hline 1 & 8.41 & 7.67 & 7.54 \\
2 & 7.78 & 7.58 & 7.21 \\
3 & 7.47 & 6.68 & 6.77 \\
\hline
\end{tabular}

cycle also increases and an obvious reduction can be seen in the tangential modulus for each unloading cycle. In contrast, both the loading and unloading tangential moduli for Type 2 tests decrease at higher cycle numbers. In addition, the loading cycle tangential moduli for specimens tested under Type 2 tests show a dramatic decline when the sample is near failure. This is caused by the rapid development of irreversible damage.

In order to further investigate the damage caused by cyclic loading, (2) is used to calculate the damage variable for each loading cycle for Type 1 and Type 2 tests. For these calculations, the maximum loading tangential modulus from the cyclic loading tests is selected as the elastic modulus for intact sandstone. This is $9.92 \mathrm{GPa}$, the maximum stress point 


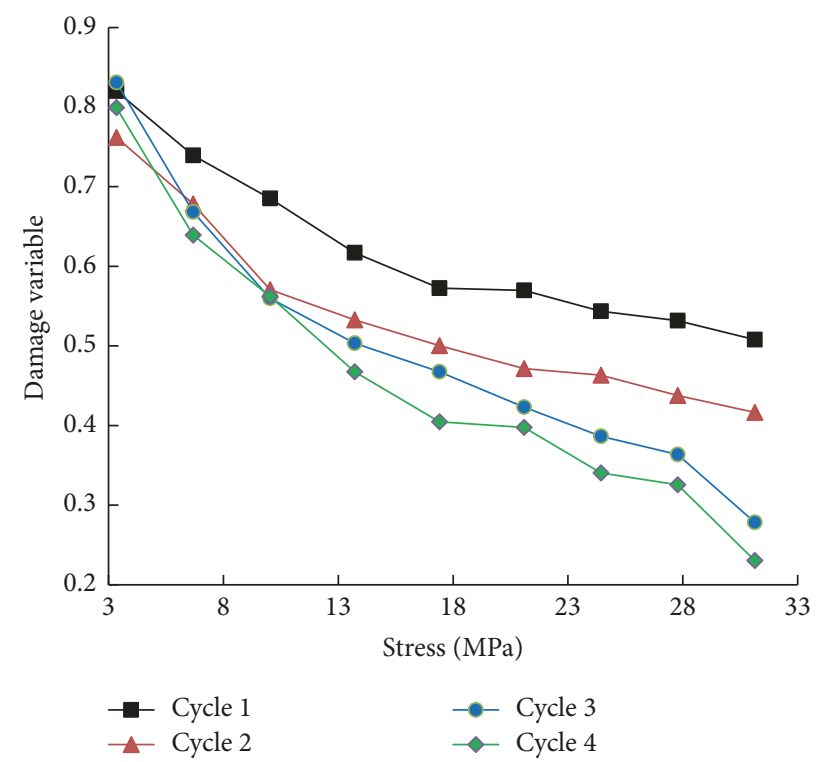

(a)

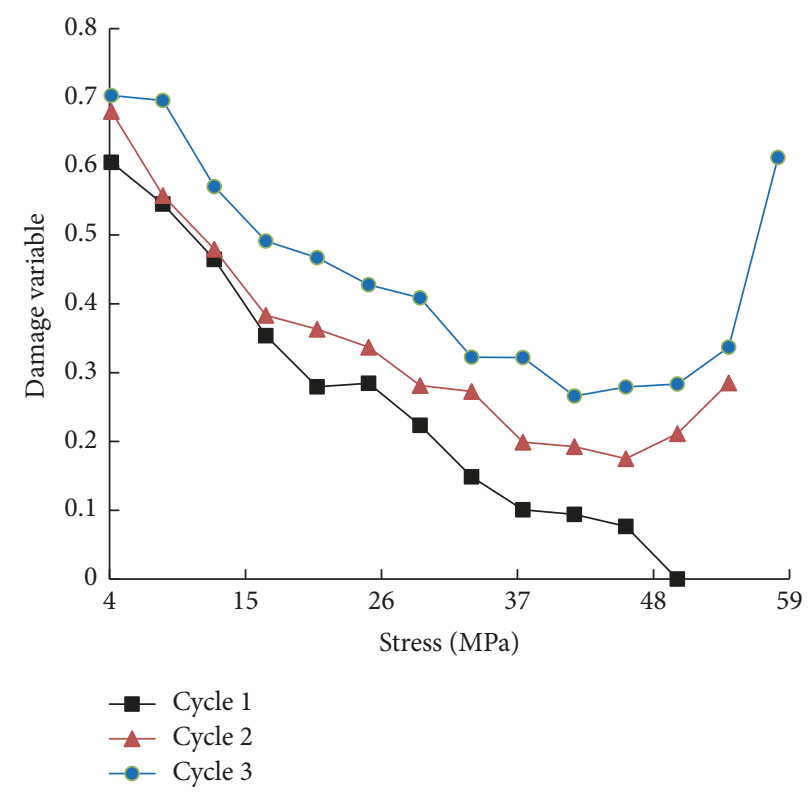

(b)

FiguRE 7: Graphs showing damage variables versus axial stress for the loading cycles of (a) Type 1 tests; (b) Type 2 tests.

for Cycle 1 of a Type 2 cyclic loading test. As illustrated in Figure 7, the preexisting defects (the pores and cracks formed during geological events and specimen preparation) in specimens are deemed the initial damage. Increasing stress gradually closes preexisting defects resulting in a general descending trend for the damage variable, but at higher stresses during Type 2 tests, the damage variable increases, implying that the high stresses have caused cracks to be initiated and propagate. Figure 7 also shows that, with increasing cycle number, the progression of the damage variable for Type 1 and Type 2 tests is different. For Type 1 tests, the damage variable consistently decreases as the number of cycles increases, implying that compaction is taking place. On the other hand, the damage variable for Type 2 tests clearly increases at higher cycle numbers indicating continuous damage accumulation.

4.2. Responses of Ultrasonic Wave Velocities to Cyclic Loading. During each cyclic loading test, the P- and S-wave signals at an ultrasonic frequency of hundreds of thousands of $\mathrm{Hz}$ were acquired using the ultrasonic transducers shown in Figure 2(b). Figures 8 and 9 show graphs of the ultrasonic velocities for Types 1 and Type 2 tests plotted against stress. Similar to the tangential moduli shown in Figure 6, both the P- and S-wave velocities generally raise with increasing axial stress; however the wave signals do show some different responses to the number of test cycles.

Figure 8 demonstrates that as the cycle number increases, the P-wave velocity gradually decreases but the S-wave velocity remains relatively constant. This implies that cyclic loading below the elastic limit does cause damage but the form of the damage leads to differences in the velocities. The elastic modulus $E_{0}$ and the shear modulus $\mu$ can be expressed as [41]

$$
\begin{aligned}
E_{0} & =\frac{\rho V_{\mathrm{s}}^{2}\left(3 V_{\mathrm{P}}^{2}-4 V_{\mathrm{S}}^{2}\right)}{V_{\mathrm{P}}^{2}-V_{\mathrm{S}}^{2}}, \\
\mu & =\rho V_{\mathrm{s}}^{2},
\end{aligned}
$$

where $\rho$ is the density, $V_{\mathrm{p}}$ is the $\mathrm{P}$-wave velocity, and $V_{\mathrm{s}}$ is the $\mathrm{S}$-wave velocity. Therefore, the decreasing $\mathrm{P}$-wave velocity and the steady $\mathrm{S}$-wave velocity indicate that the damage in the specimen reduced the dynamic Young's modulus but had only a slight influence on the dynamic shear modulus. The decrease in dynamic Young's modulus is contrary to the stiffening trend from loading shown by Figure 6(a) but consistent with the softening trend of unloading in Figure 6(b). It is well known that the P-wave velocity is more sensitive to the development of cracks oriented perpendicular to the direction of wave travel (in this case, wave travel is parallel to vertically applied load), whereas the S-wave velocity is more sensitive to the cracks oriented parallel to the direction of wave travel [42-44]. Therefore, the decrease in P-wave velocities indicates that low-level cyclic stress induces the initiation and development of cracks oriented horizontally or subhorizontally, and the more stable $S$-wave velocity means that few irreversible microstructural changes are oriented in a vertical direction. Considering the stiffening trend during loading and the softening trend during unloading suggested by Figures 6(a) and 6(b), it is reasonable to attribute the development of horizontal cracks to the collapses of pores. The collapses would cause the relocation of sandstone grains and result in a densification of the rock. The denser structure means the specimen would stiffen during loading, but the rebound during unloading would be limited. Furthermore, the gradual decrease in P-wave velocity in Figures 8(a) and 8(b) indicates a progressive development of horizontal cracks. 


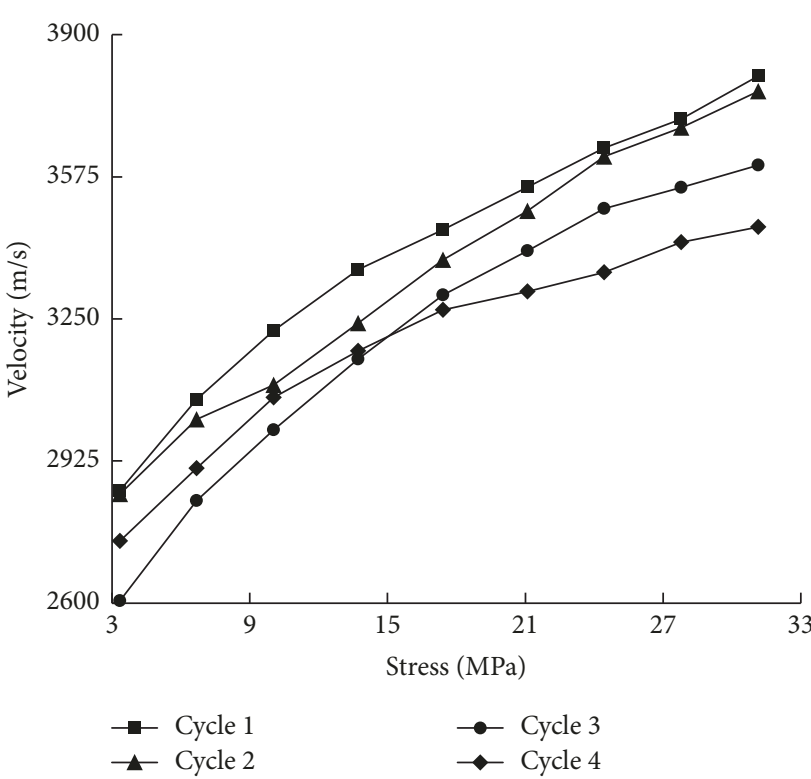

(a)

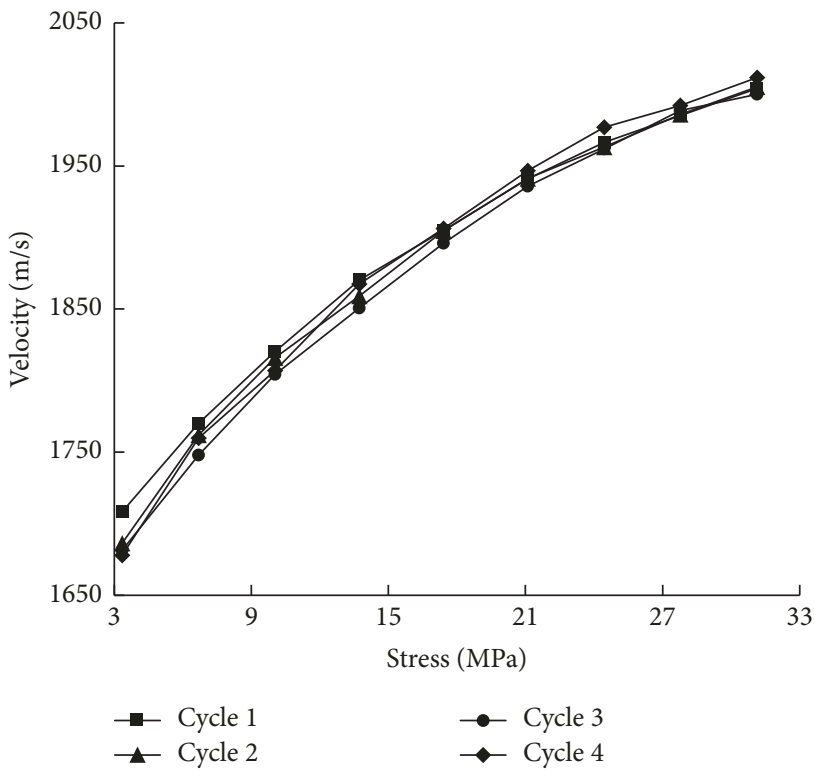

(c)

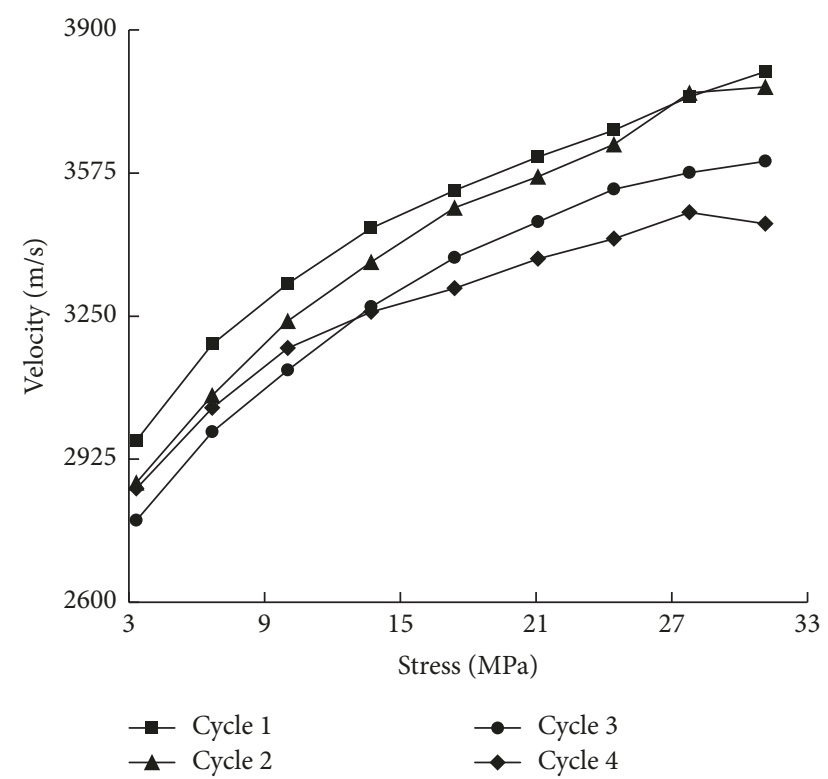

(b)

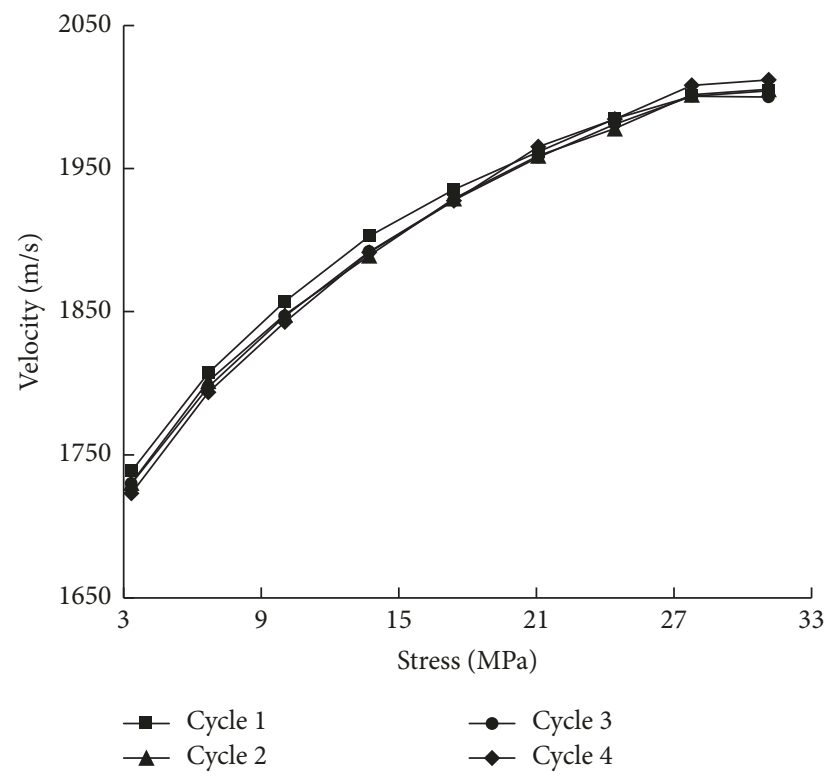

(d)

Figure 8: Graphs showing P- and S-wave velocities versus axial stress for Type 1 tests. (a) Loading stage P-wave velocities; (b) unloading stage P-wave velocities; (c) loading stage S-wave velocities; (d) unloading stage S-wave velocities.

This progressive crack formation is a clear indication of fatigue damage.

Similar to the trends of the tangential moduli with increasing axial stress in Figures 6(c) and 6(d), Figures 9(a) and 9(c) both show obvious velocity declines at high stress values. The decline indicates that, at these stress levels, damage develops rapidly in the rock's microstructure and this clearly indicates brittle behavior. During Cycle 3 loading, the sudden failure of the specimen at $58.3 \mathrm{MPa}$ resulted in no data being collected at higher stresses; otherwise there would be a similar velocity decline at the right end of the
Cycle 3 curves in Figure 9. This ultrasonic velocity behavior conforms to the Kaiser Effect [45] and reveals that the rate of damage accumulation during Type 2 loading rapidly accelerates when the former maximum applied stress is exceeded. This rapid accumulation of damage can also be demonstrated by the change in $\mathrm{P}$-wave velocities during the whole loading-unloading test. As shown in Figure 10 for Type 2 tests, the P-wave velocity for any single stress value is higher during loading than it is for unloading, but just the opposite is true for Type 1 tests. The decrease in velocity shows that the rock's microstructure had suffered considerable damage at 


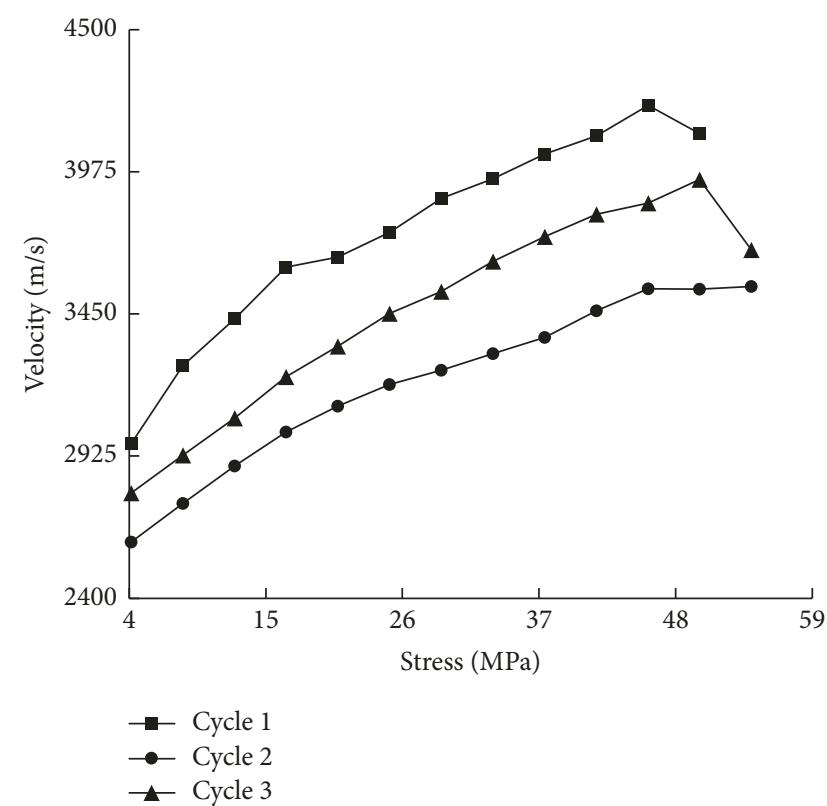

(a)

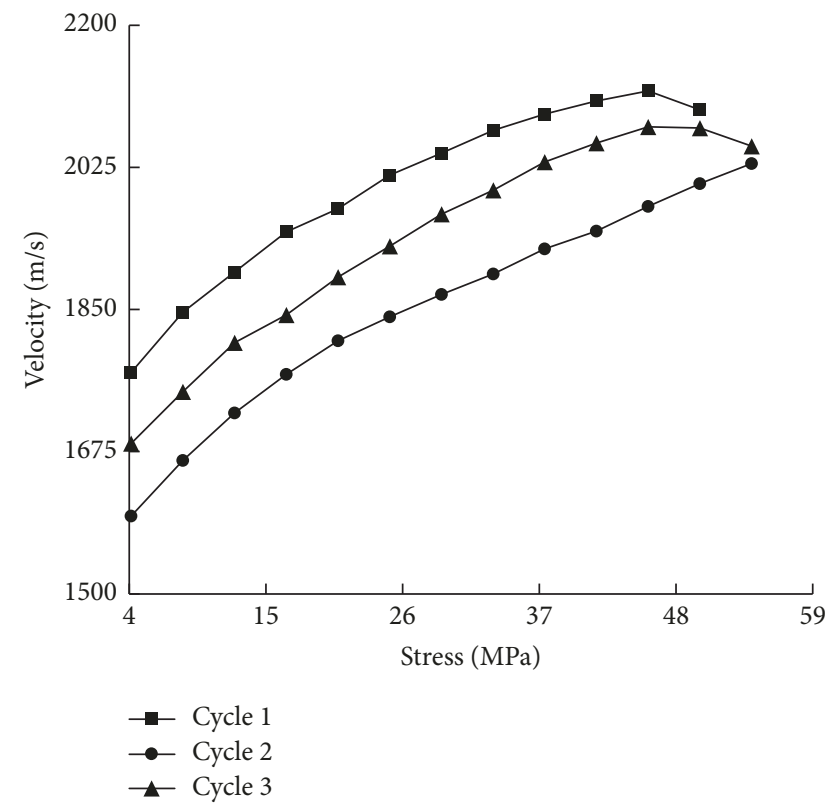

(c)

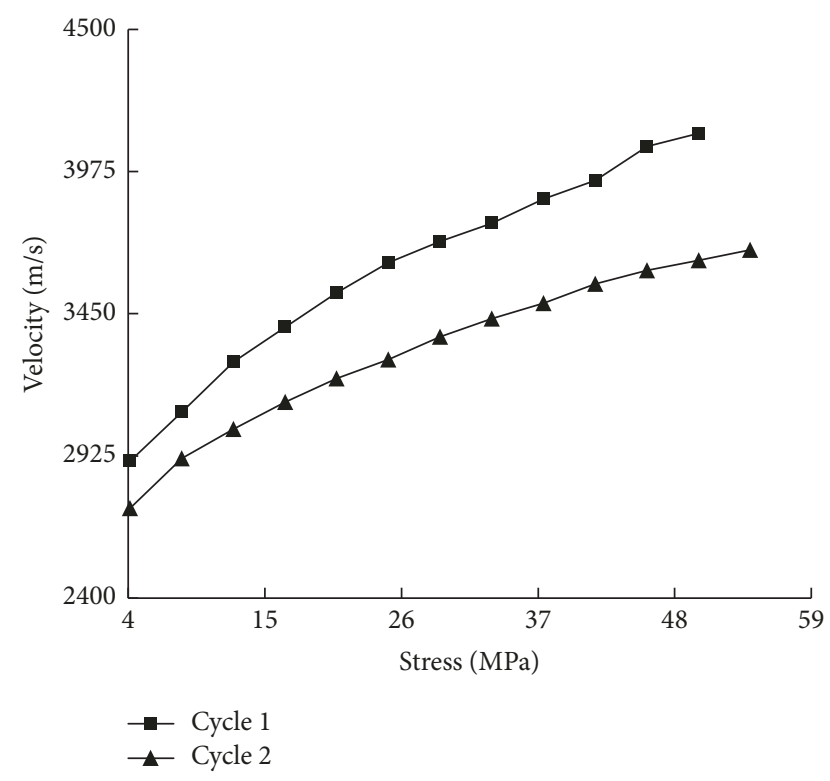

(b)

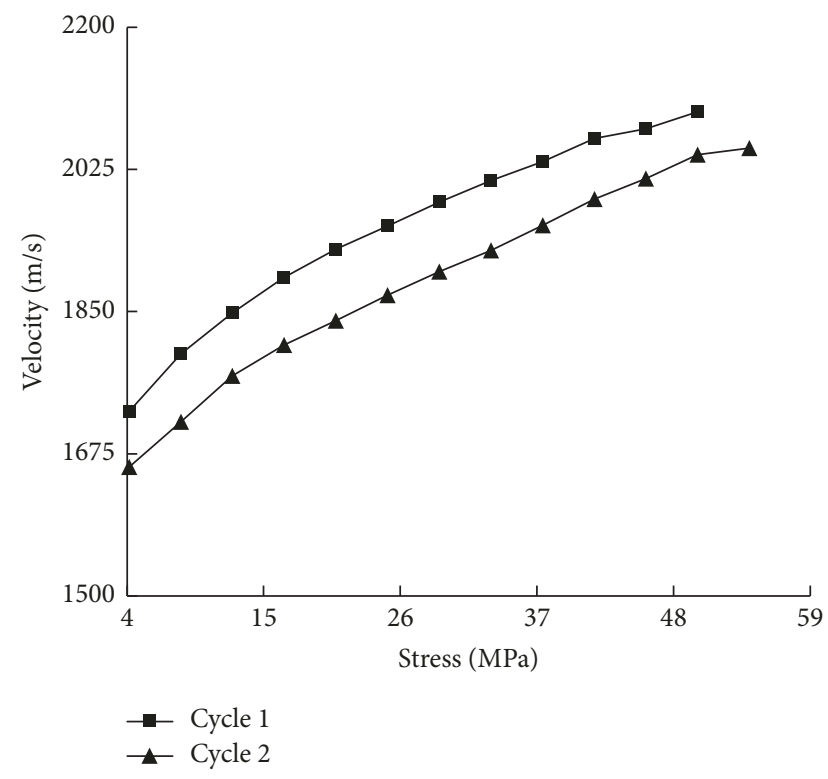

(d)

Figure 9: P- and S-wave velocities versus axial stress for Type 2 tests. (a) Loading stage P-wave velocities, (b) unloading stage P-wave velocities, (c) loading stage $\mathrm{S}$-wave velocities, (d) and unloading stage $\mathrm{S}$-wave velocities.

the higher stress levels. Nevertheless, the increase in velocities during Type 1 testing is still the result of the densification described above.

In order to quantify the deformation of the microstructure, a crack density parameter (developed by Ayling [46]; Ayling et al. [47]) is introduced that uses three dimensionless parameters $\left(\ni_{1}, \ni_{2}, \ni_{3}\right)$ to describe cracking anisotropy. Cracking anisotropy can be expresses as

$$
\begin{aligned}
& \ni_{3}=4.28\left(1-\left(\frac{V_{\mathrm{S}}}{V_{\mathrm{S} 0}}\right)^{2}\right)-1.77\left(1-\left(\frac{V_{\mathrm{P}}}{V_{\mathrm{P} 0}}\right)^{2}\right), \\
& \ni_{1}=0.92\left(1-\left(\frac{V_{\mathrm{P}}}{V_{\mathrm{P} 0}}\right)^{2}\right)-0.57\left(1-\left(\frac{V_{\mathrm{S}}}{V_{\mathrm{S} 0}}\right)^{2}\right) .
\end{aligned}
$$

In (4), $\ni_{3}$ (equal to $\ni_{2}$ for uniaxial compression) denotes the crack density for cracks aligned parallel to the loading 


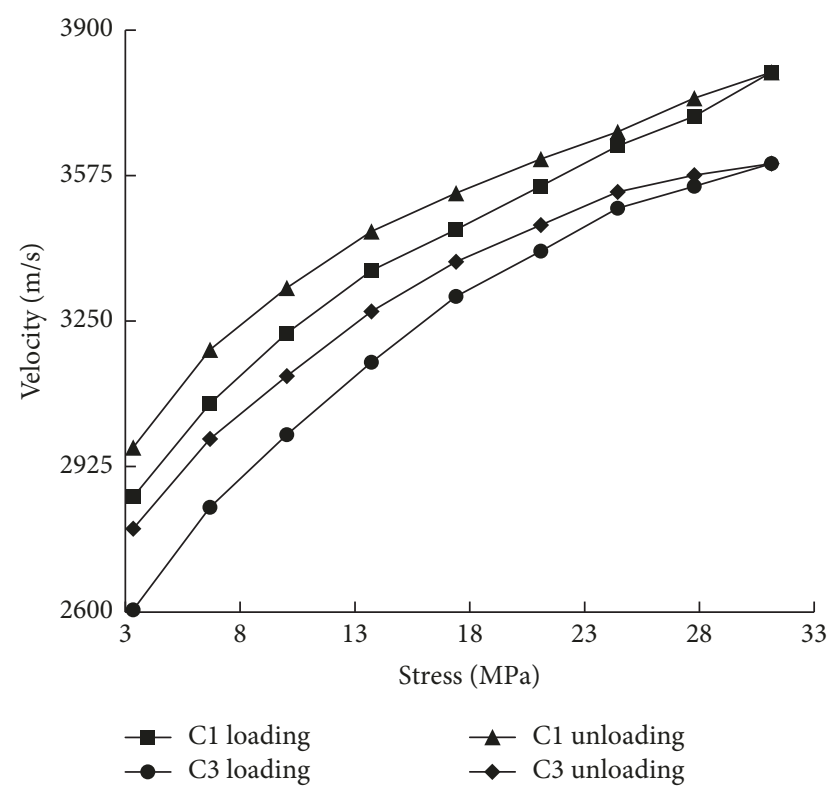

(a)

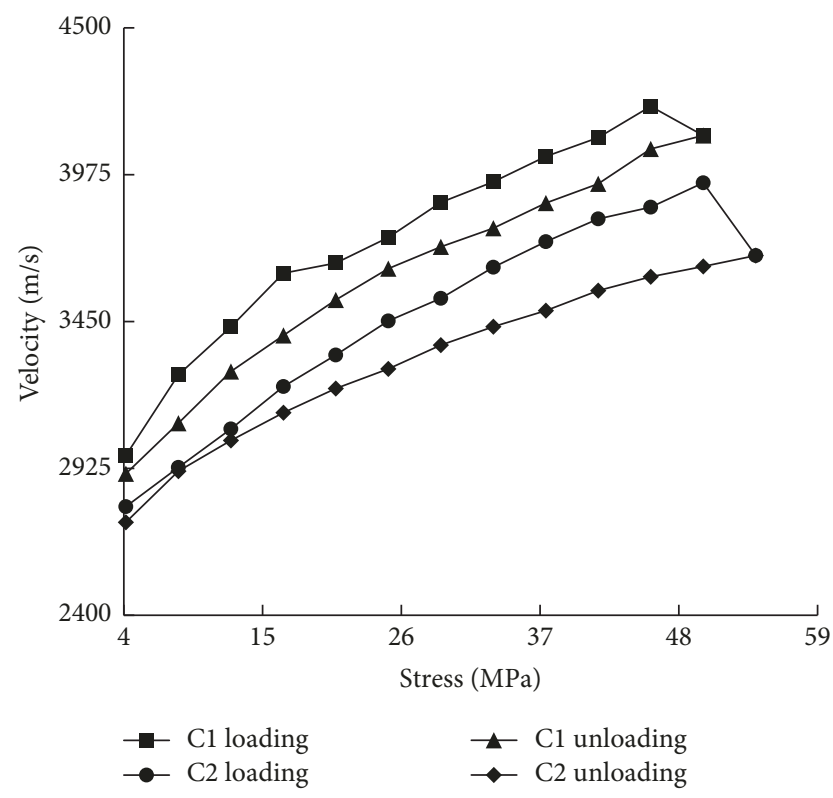

(b)

Figure 10: P-wave velocity evolution during loading and unloading. (a) Cycles 1 and 3 from Type 1 testing; (b) Cycles 1 and 2 from Type 2 testing.

direction, $\ni_{1}$ denotes the crack density for cracks aligned perpendicularly to loading direction, and $V_{\mathrm{P} 0}$ and $V_{\mathrm{S} 0}$ are, respectively, the $\mathrm{P}$ - and $\mathrm{S}$-wave velocities of the noncracked solid. In this case, $V_{\mathrm{P} 0}$ and $V_{\mathrm{S} 0}$ are the maximum velocities measured under Type 1 loading (meaning that the pores and cracks in the rock are supposed to be closed). Because Type 1 loading did not exceed the elastic limit, the highest stress condition under Type 1 loading (where the maximum velocity values were recorded) was expected to close the vast majority of cracks and not initiate any new cracks.

The changes in the crack density parameter during cyclic loading have been determined using (4) and are shown in Figure 11. The general trends in crack density are shown by the density parameter at three stress values, values that represent low, medium, and high stresses. From Figures 11(a) and 11(b) it can be seen that the microstructural evolution during Type 1 cyclic loading exhibits different tendencies in the directions parallel with and perpendicular to the loading axis. The reduction in $\ni_{3}$ as the number of loading steps increases indicates that the applied stress tends to close the cracks that are aligned parallel to the loading axis. This is counterintuitive. We attribute this to the compaction of clay minerals in the sandstone; specifically, the compression squeezes the quartz grains against the intergranular clay minerals forcefully closing the microcracks. This compression stiffens the sandstone but lessens its capacity for rebound. This is confirmed by the increase in tangential moduli from cycle to cycle shown in Figure 6(a) and their reduction in Figure 6(b). In contrast, the step-wise escalation of $\ni_{1}$ in Figure 11(b) suggests that the loading stage gradually increases the number of cracks oriented perpendicular to the loading axis. As described previously, a continuously applied stress would close the horizontal cracks, but the cyclic loading-unloading causes the cracks to repeatedly close and open, leading to fatigue failure and elongation of the existing cracks. This is reflected by the decrease in $\mathrm{P}$-wave velocities as the number of cycles increases, as shown in Figure 8(a). Crack densities during Type 2 loading, illustrated in Figures 11(c) and $11(\mathrm{~d})$, show an increase of both $\ni_{3}$ and $\ni_{1}$, implying that, for this style of loading, crack density and damage increase continuously.

\section{Conclusions}

The influence of the two types of cyclic loading on the damage evolution of sandstone was investigated. Based on the differences in elastic moduli and ultrasonic wave velocities, attributes of microstructural deformation were identified. The main findings are as follows:

(1) Low-level cyclic loading caused the specimens to stiffen during loading but soften during unloading. The stiffness degradation method does not describe the accumulated damage satisfactorily, but P-wave velocities clearly reflect the damage development.

(2) The energy dissipated by damage and plastic deformation decreases as the number of loading cycles increases for Type 1 loading, but energy dissipation remains relatively constant for Type 2 loading. The decrease during Type 1 tests can be attributed to the plastic closure of preexisting pores and cracks caused by the low-level cyclic loading. This loading results in a continuous reduction of the number of open pores and cracks. The relatively stable dissipated energy from Type 2 loading results from the accumulation of irreversible damage. 


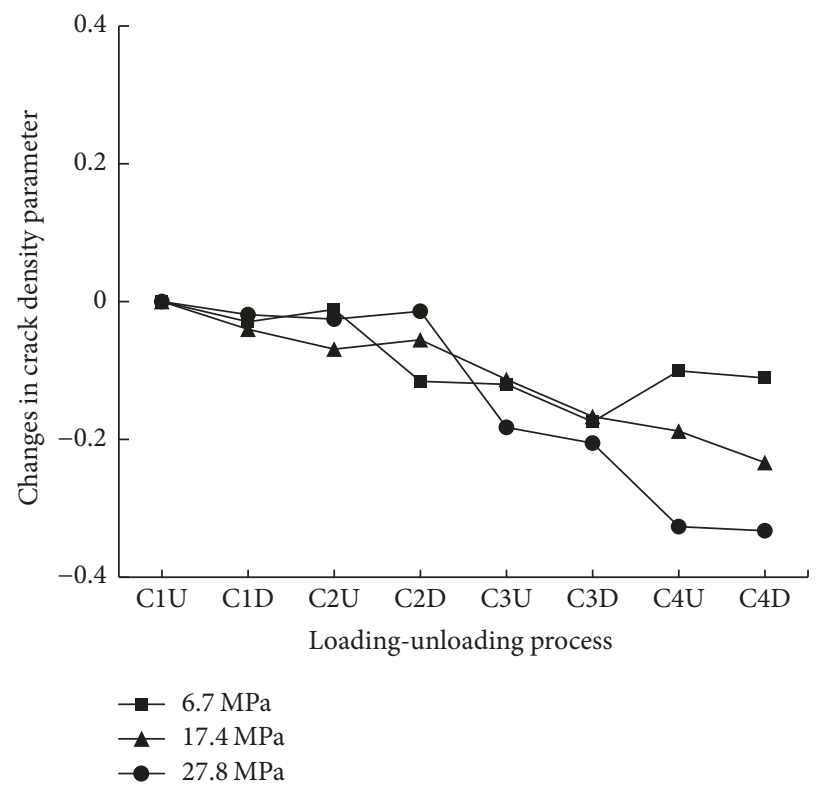

(a)

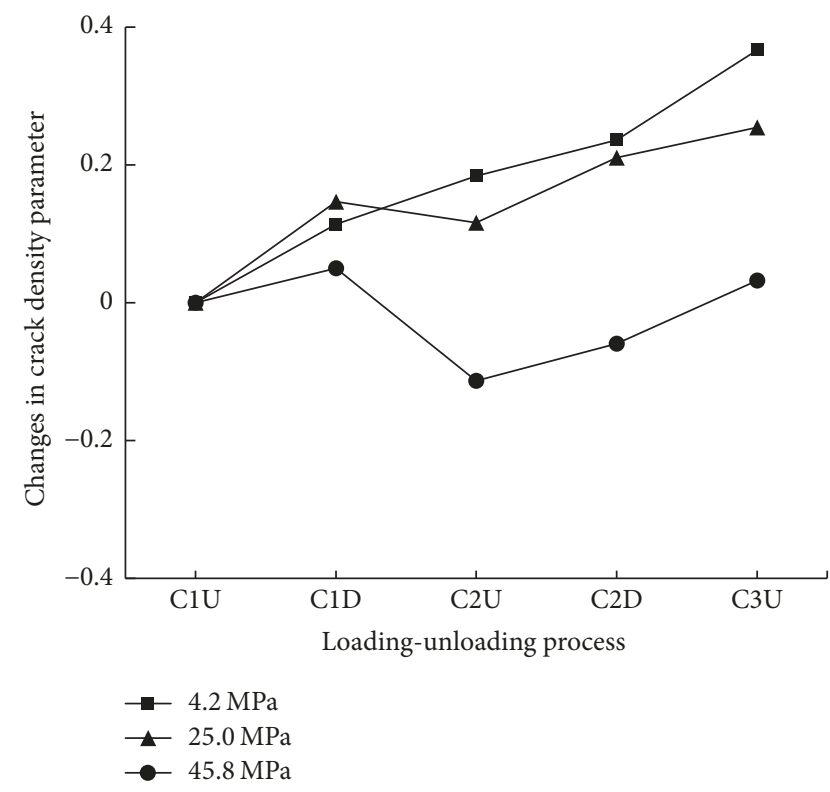

(c)

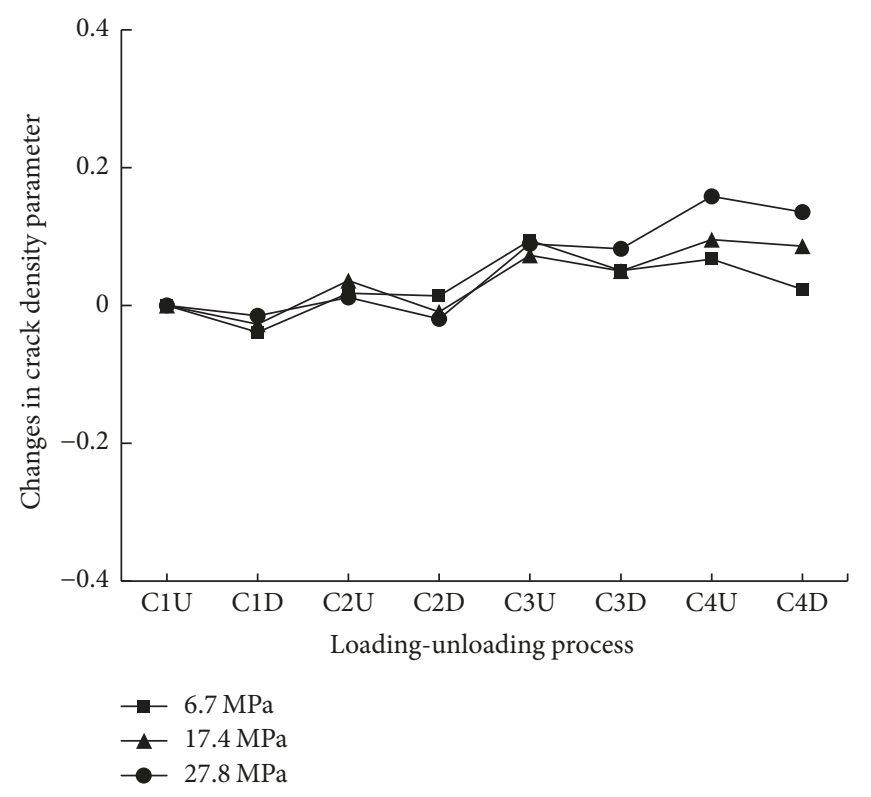

(b)

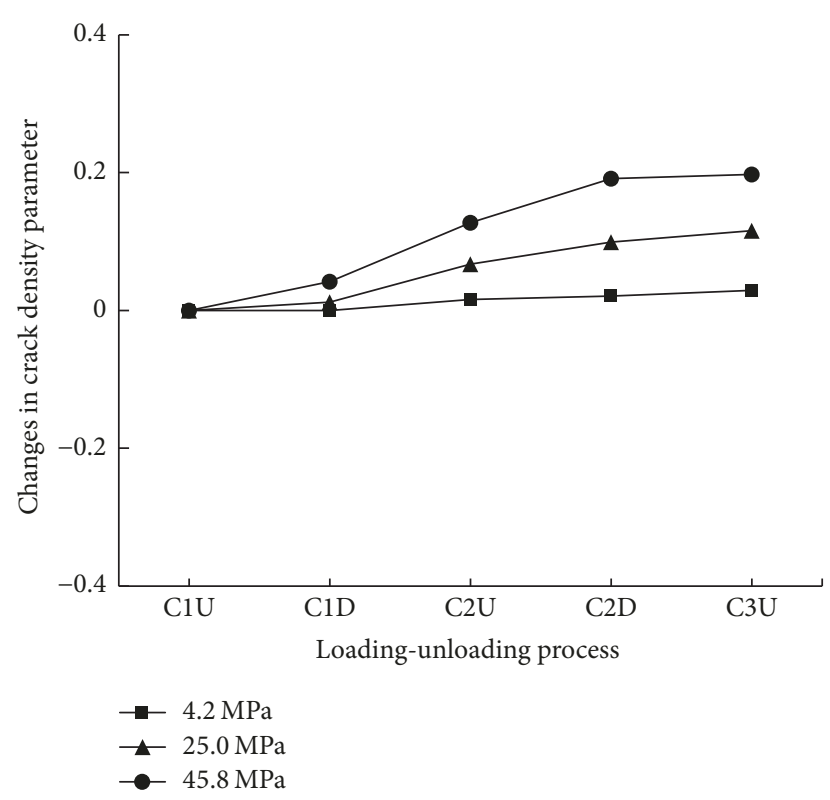

(d)

FIGURE 11: Graphs showing changes in the crack density parameter at three selected stresses representing low, medium, and high stress values during loading and unloading. Crack density parameter $\ni_{3}$ denotes cracks parallel to the load direction, parameter $\ni_{1}$ denotes perpendicular cracks. (a) $\ni_{3}$ for Type 1 tests, (b) $\ni_{1}$ for Type 1 tests, (c) $\ni_{3}$ for Type 2 tests, and (d) $\ni_{1}$ for Type 2 tests. The units on the $x$-axis are the loading-unloading stages (e.g., C2U stands for Cycle 2 unloading).

(3) Low-level cyclic loading enhances the anisotropy of cracking. This anisotropy results from the compression of intergranular clay minerals and cracks developed by fatigue failure.

(4) The irreversible damage accumulated during cyclic loading with an increasing upper stress limit is the consequence of brittle failure in the sandstone's microstructure.

\section{Conflicts of Interest}

The authors declare that they have no conflicts of interest.

\section{Acknowledgments}

This work was financially supported by Program IRT_14R55 for Innovative Research Team in University by Ministry of Education of China, the Natural Science Foundation 
of Jiangsu Province under Contract no. BK20151145, and the National Natural Science Foundation of China under Contract no. 51704277.

\section{References}

[1] D. D. Tannant, R. K. Brummer, and X. Yi, "Rockbolt behaviour under dynamic loading: Field tests and modelling," International Journal of Rock Mechanics and Mining Sciences, vol. 32, no. 6, pp. 537-550, 1995.

[2] A. Cao, L. Dou, W. Cai, S. Gong, S. Liu, and G. Jing, "Case study of seismic hazard assessment in underground coal mining using passive tomography," International Journal of Rock Mechanics and Mining Sciences, vol. 78, pp. 1-9, 2015.

[3] M. He, N. Li, Y. Chen, and C. Zhu, "Strength and fatigue properties of sandstone under dynamic cyclic loading," Shock and Vibration, vol. 2016, Article ID 9458582, 8 pages, 2016.

[4] X. S. Liu, J. G. Ning, Y. L. Tan, and Q. H. Gu, "Damage constitutive model based on energy dissipation for intact rock subjected to cyclic loading," International Journal of Rock Mechanics and Mining Sciences, vol. 85, pp. 27-32, 2016.

[5] X. Li, Z. Zhou, T.-S. Lok, L. Hong, and T. Yin, "Innovative testing technique of rock subjected to coupled static and dynamic loads," International Journal of Rock Mechanics and Mining Sciences, vol. 45, no. 5, pp. 739-748, 2008.

[6] M. Azadi and S. M. M. Hosseini, "The uplifting behavior of shallow tunnels within the liquefiable soils under cyclic loadings," Tunnelling and Underground Space Technology, vol. 25, no. 2, pp. 158-167, 2010.

[7] J. Nemcik, A. Mirzaghorbanali, and N. Aziz, "An elasto-plastic constitutive model for rock joints under cyclic loading and constant normal stiffness conditions," Geotechnical and Geological Engineering, vol. 32, no. 2, pp. 321-335, 2014.

[8] X. Leng, J. Liu, Z. Cui, and Q. Sheng, "Study on failure characteristics of basalt subjected to triaxial cyclic loading," Applied Mechanics and Materials, vol. 204-208, pp. 405-409, 2012.

[9] E. Liu and S. He, "Effects of cyclic dynamic loading on the mechanical properties of intact rock samples under confining pressure conditions," Engineering Geology, vol. 125, no. 27, pp. 81-91, 2012.

[10] L.-J. Ma, X.-Y. Liu, M.-Y. Wang et al., "Experimental investigation of the mechanical properties of rock salt under triaxial cyclic loading," International Journal of Rock Mechanics \& Mining Sciences, vol. 62, pp. 34-41, 2013.

[11] N. Gatelier, F. Pellet, and B. Loret, "Mechanical damage of an anisotropic porous rock in cyclic triaxial tests," International Journal of Rock Mechanics and Mining Sciences, vol. 39, no. 3, pp. 335-354, 2002.

[12] M. V. M. S. Rao and Y. V. Ramana, "A study of progressive failure of rock under cyclic loading by ultrasonic and AE monitoring techniques," Rock Mechanics and Rock Engineering, vol. 25, no. 4, pp. 237-251, 1992.

[13] C. A. Tang and P. K. Kaiser, "Numerical simulation of cumulative damage and seismic energy release during brittle rock failure-part I: fundamentals," International Journal of Rock Mechanics and Mining Sciences, vol. 35, no. 2, pp. 113-121, 1998.

[14] M. Cai, P. K. Kaiser, and C. D. Martin, "Quantification of rock mass damage in underground excavations from microseismic event monitoring," International Journal of Rock Mechanics and Mining Sciences, vol. 38, no. 8, pp. 1135-1145, 2001.
[15] H. Xie, L. Li, Y. Ju, R. Peng, and Y. Yang, "Energy analysis for damage and catastrophic failure of rocks," Science China Technological Sciences, vol. 54, no. 1, pp. 199-209, 2011.

[16] J. Liu, H. Xie, Z. Hou, C. Yang, and L. Chen, "Damage evolution of rock salt under cyclic loading in unixial tests," Acta Geotechnica, vol. 9, no. 1, pp. 153-160, 2014.

[17] J. S. Kim, K. S. Lee, W. J. Cho, H. Choi, and G. Cho, "A comparative evaluation of stress-strain and acoustic emission methods for quantitative damage assessments of brittle rock," Rock Mechanics and Rock Engineering, vol. 48, no. 2, pp. 495508, 2015.

[18] R. Peng, Y. Ju, J. G. Wang, H. Xie, F. Gao, and L. Mao, "Energy Dissipation and Release During Coal Failure Under Conventional Triaxial Compression," Rock Mechanics and Rock Engineering, vol. 48, no. 2, pp. 509-526, 2014.

[19] H. P. Xie, Y. Ju, L. Y. Li, and R. D. Peng, "Energy mechanism of deformation and failure of rock masses," Chinese Journal of Rock Mechanics and Engineering, vol. 27, no. 9, pp. 1729-1739, 2008 (Chinese).

[20] J. Lemaitre, "A continuous damage mechanics model for ductile fracture," Journal of Engineering Materials and Technology, vol. 107, no. 1, pp. 83-89, 1985.

[21] C. H. Scholz and T. A. Koczynski, "Dilatancy anisotropy and the response of rock to large cyclic loads," Journal of Geophysical Research: Atmospheres, vol. 84, no. 10, pp. 5525-5534, 1979.

[22] C. D. Martin, "The effect of cohesion loss and stress path on brittle rock strength," Canadian Geotechnical Journal, vol. 34, no. 5, pp. 698-725, 1997.

[23] L. S. Costin and D. J. Holcomb, “Time-dependent failure of rock under cyclic loading," Tectonophysics, vol. 79, no. 3-4, pp. 279296, 1981.

[24] Z. Tao and H. Mo, "An experimental study and analysis of the behaviour of rock under cyclic loading," International Journal of Rock Mechanics and Mining Sciences and Geomechanics Abstracts, vol. 27, no. 1, pp. 51-56, 1990.

[25] C. D. Martin and N. A. Chandler, "The progressive fracture of Lac du Bonnet granite," International Journal of Rock Mechanics and Mining Sciences and Geomechanics Abstracts, vol. 31, no. 6, pp. 643-659, 1994.

[26] S. K. Ray, M. Sarkar, and T. N. Singh, "Effect of cyclic loading and strain rate on the mechanical behaviour of sandstone," International Journal of Rock Mechanics and Mining Sciences, vol. 36, no. 4, pp. 543-549, 1999.

[27] M. K. Jafari, F. Pellet, M. Boulon, and K. A. Hosseini, "Experimental study of mechanical behaviour of rock joints under cyclic loading," Rock Mechanics and Rock Engineering, vol. 37, no. 1, pp. 3-23, 2004.

[28] X. T. Feng, P. Z. Pan, and H. Zhou, "Simulation of the rock microfracturing process under uniaxial compression using an elasto-plastic cellular automaton," International Journal of Rock Mechanics and Mining Sciences, vol. 43, no. 7, pp. 1091-1108, 2006.

[29] K. Khaledi, E. Mahmoudi, M. Datcheva, and T. Schanz, "Stability and serviceability of underground energy storage caverns in rock salt subjected to mechanical cyclic loading," International Journal of Rock Mechanics and Mining Sciences, vol. 86, pp. 115131, 2016.

[30] N. Li, W. Chen, P. Zhang, and G. Swoboda, "The mechanical properties and a fatigue-damage model for jointed rock masses subjected to dynamic cyclical loading," International Journal of Rock Mechanics and Mining Sciences, vol. 38, no. 7, pp. 1071-1079, 2001. 
[31] M. N. Bagde and V. Petroš, "Fatigue and dynamic energy behaviour of rock subjected to cyclical loading," International Journal of Rock Mechanics and Mining Sciences, vol. 46, no. 1, pp. 200-209, 2009.

[32] J. Q. Xiao, D. X. Ding, F. L. Jiang, and G. Xu, "Fatigue damage variable and evolution of rock subjected to cyclic loading," International Journal of Rock Mechanics and Mining Sciences, vol. 47, no. 3, pp. 461-468, 2010.

[33] J. Fan, J. Chen, D. Jiang, S. Ren, and J. Wu, "Fatigue properties of rock salt subjected to interval cyclic pressure," International Journal of Fatigue, vol. 90, pp. 109-115, 2016.

[34] Y. Guéguen and A. Schubnel, "Elastic wave velocities and permeability of cracked rocks," Tectonophysics, vol. 370, no. 1-4, pp. 163-176, 2003.

[35] I. N. Gupta, "Seismic velocities in rock subjected to axial loading up to shear fracture," Journal of Geophysical Research: Atmospheres, vol. 78, no. 29, pp. 6936-6942, 1973.

[36] S. Stanchits, S. Vinciguerra, and G. Dresen, "Ultrasonic velocities, acoustic emission characteristics and crack damage of basalt and granite," Pure and Applied Geophysics, vol. 163, no. 5-6, pp. 974-993, 2006.

[37] Z. T. Bieniawski and M. J. Bernede, "Suggested methods for determining the uniaxial compressive strength and deformability of rock materials. Part 1. Suggested method for determination of the uniaxial compressive strength of rock materials," International Journal of Rock Mechanics and Mining Sciences, vol. 16, no. 2, p. 137, 1979.

[38] D. T. Griggs, "The factor of fatigue in rock exfoliation," The Journal of Geology, vol. 44, no. 7, pp. 783-796, 1936.

[39] M. L. Kachanov, "A microcrack model of rock inelasticity part I: Frictional sliding on microcracks," Mechanics of Materials, vol. 1, no. 1, pp. 19-27, 1982.

[40] J. W. Zhou, W. Y. Xu, and X. G. Yang, "A microcrack damage model for brittle rocks under uniaxial compression," Mechanics Research Communications, vol. 37, no. 4, pp. 399-405, 2010.

[41] G. Mavko, T. Mukerji, and J. Dvorkin, The Rock Physics Handbook: Tools for Seismic Analysis of Porous Media, Cambridge University Press, Cambridge, UK, 2009.

[42] J. A. Hudson, "Wave speeds and attenuation of elastic waves in material containing cracks," The Geophysical Journal of the Royal Astronomical Society, vol. 64, no. 1, pp. 133-150, 1981.

[43] C. M. Sayers, "Inversion of ultrasonic wave velocity measurements to obtain the microcrack orientation distribution function in rocks," Engineering Fracture Mechanics, vol. 35, no. 4-5, pp. 743-749, 1990.

[44] M. G. Ezersky, "Behavior of seismic-acoustic parameters during deforming and failure of rock samples, large blocks and underground opening: base for monitoring," International Journal of Geo-Engineering, vol. 8, no. 1, p. 13, 2017.

[45] J. Kaiser, "Erkenntnisse und Folgerungen aus der Messung von Geräuschen bei Zugbeanspruchung von metallischen Werkstoffen," Steel Research International, vol. 24, no. 1-2, pp. 43-45, 1953.

[46] M. R. Ayling, An experimental study of physical property changes in crustal rocks undergoing triaxial deformation [Ph.D. dissertation], 1992.

[47] M. R. Ayling, P. G. Meredith, and S. A. F. Murrell, "Microcracking during triaxial deformation of porous rocks monitored by changes in rock physical properties, I. Elastic-wave propagation measurements on dry rocks," Tectonophysics, vol. 245, no. 3-4, pp. 205-221, 1995. 


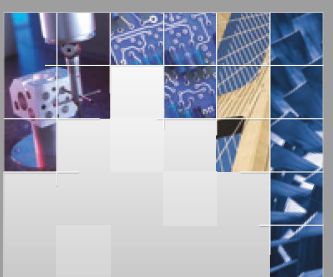

\section{Enfincering}
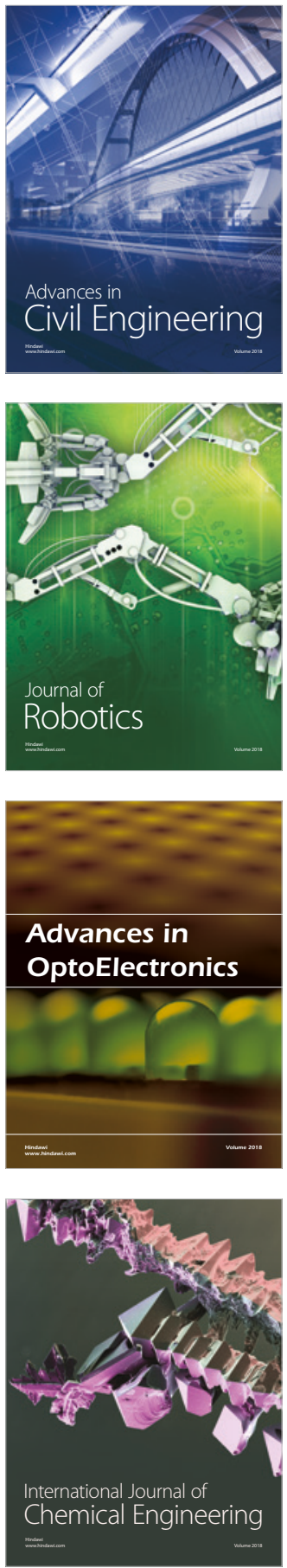

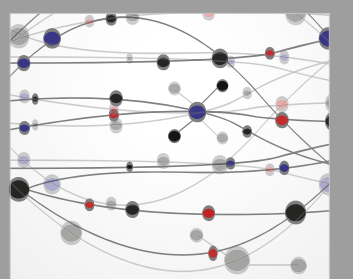

\section{Rotating \\ Machinery}

The Scientific World Journal

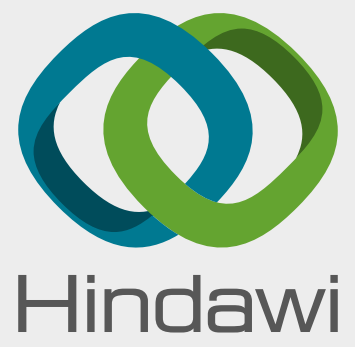

Submit your manuscripts at

www.hindawi.com
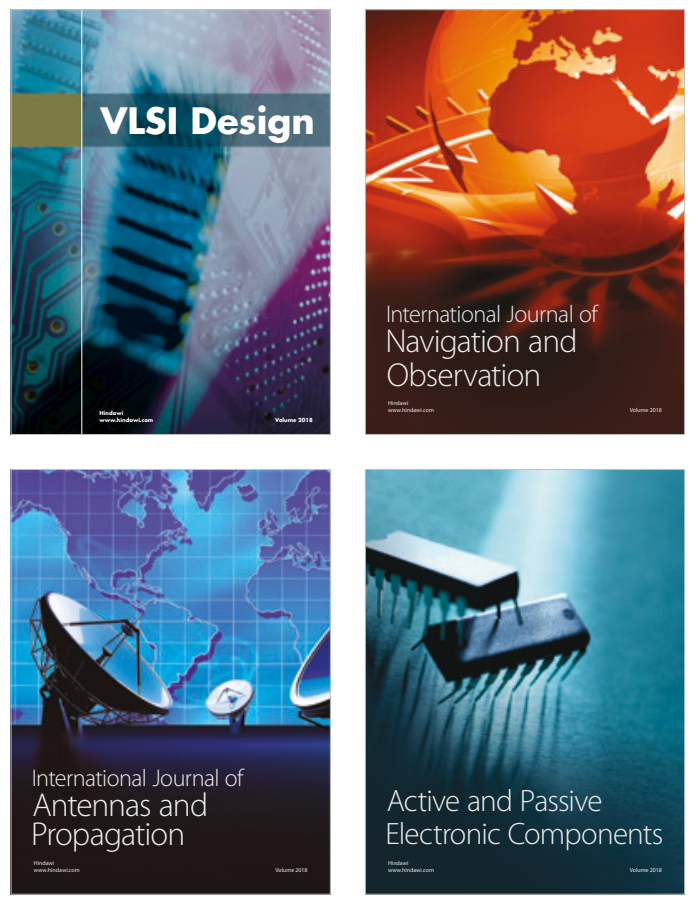
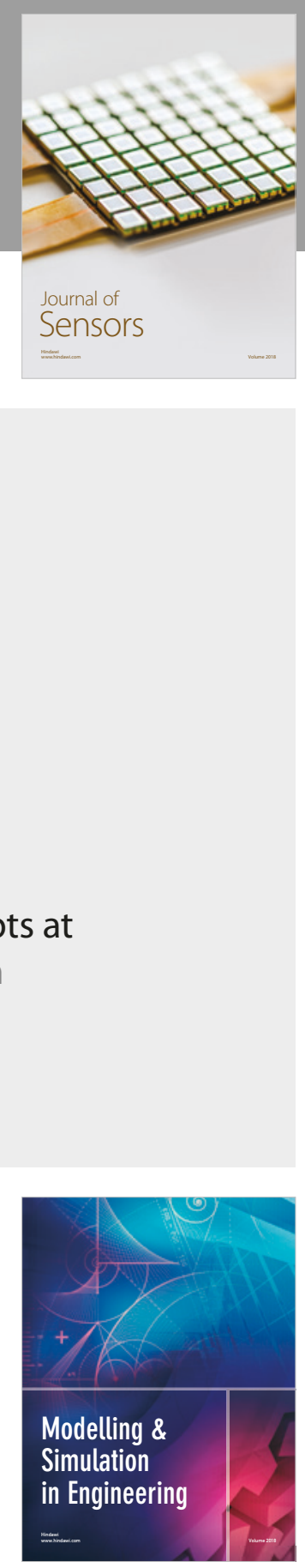

\section{Advances \\ Multimedia}
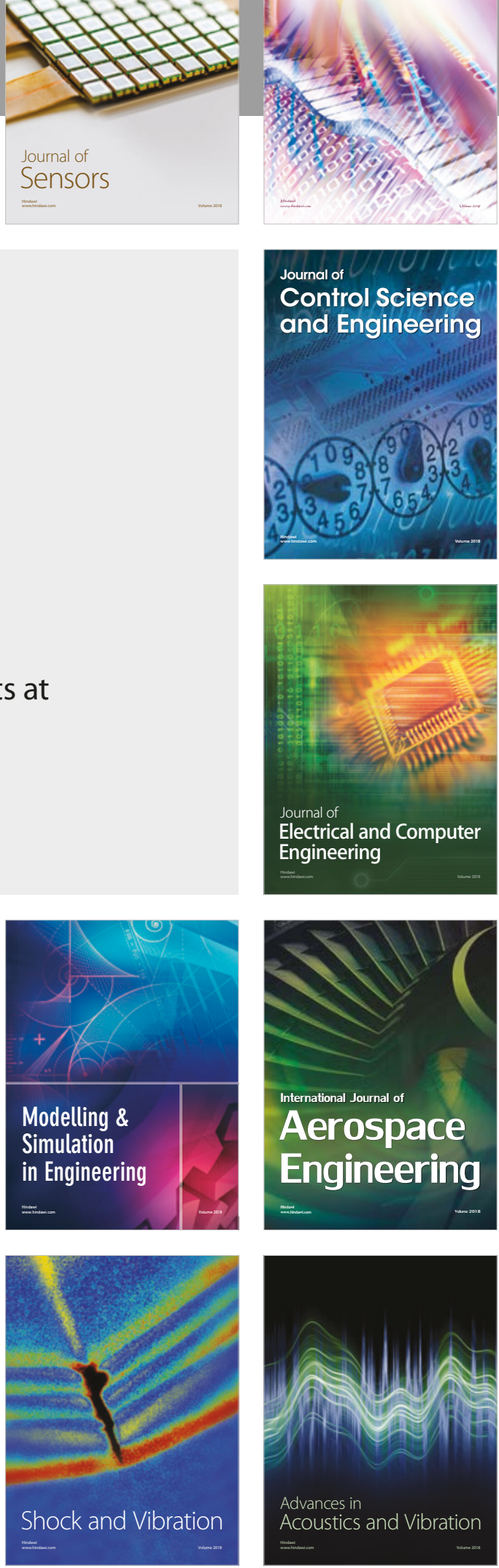